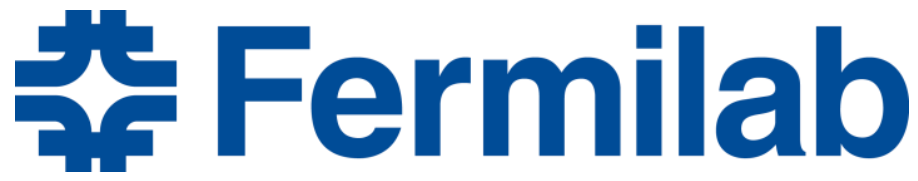

\section{Observations of Long- and Short-Range Wakefield Effects on e-Beam Dynamics in TESLA-type SCRF Cavities}

\author{
Alex Lumpkin (Fermilab) \\ Accelerator Physics Seminar at DESY \\ 03 September 2019 \\ Hamburg, Germany
}




\section{OUTLINE}

I. Introduction

II. Injector beamline and streak camera viewing optical transition radiation (OTR) screen at X121.

-Strategy of beam steering off axis into TESLA

Cavities to generate wakefields and beam effects.

III. Previous long-range wakefield test, Higher-order Modes (HOMs) context.

IV. Initial observations of short-range wakefield effects.

V. Summary. 


\section{Introduction}

- Generation and preservation of bright electron beams are two of the challenges in the accelerator community given the inherent possibility of excitations of dipolar short-range and long-range wakefields (e.g., higherorder modes (HOMs)) due to beam offsets in the accelerating cavities.

- Our primary goal is to investigate beam steering offsets and possible emittance dilution by monitoring and minimizing effects in L-band, 9-cell TESLA-type superconducting rf accelerating cavities.

- Such cavities form the drive accelerator for the FLASH FEL, the European XFEL, the under construction LCLS-II, the proposed MaRIE XFEL at Los Alamos, and the International Linear Collider under consideration in Japan.

- We report sub-micropulse effects on beam transverse position centroids correlated with off-axis beam steering in TESLA-type cavity at the Fermilab Accelerator Science and Technology (FAST) Facility.

- We used a 3-MHz micropulse repetition rate, a unique two separatedsingle-cavity configuration, and targeted diagnostics for these tests. 


\section{FAST Configuration and Unique Diagnostics Available}

- Photocathode (PC) rf Gun beam injected into TESLA Cavities.

- Two single cavities allow localization of vertical effect to mostly second cavity using corrector $\mathrm{H} / \mathrm{V} 103$ with $\mathrm{HOMs}$ minimized in CC1.

- Streak camera views the X121 and X124 OTR screens and provides $\sim 1$-ps resolution so multiple time slices in 4 sigma-t.

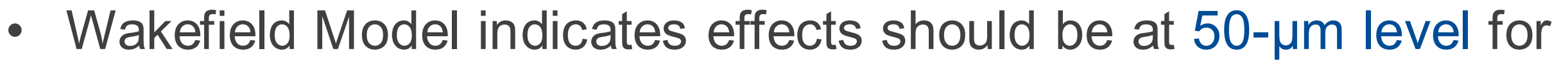
an offset of $1 \mathrm{~mm}, \sigma_{\mathrm{t}}=10 \mathrm{ps}$, and Q 2.4 nC. (V. Lebedev calc.)

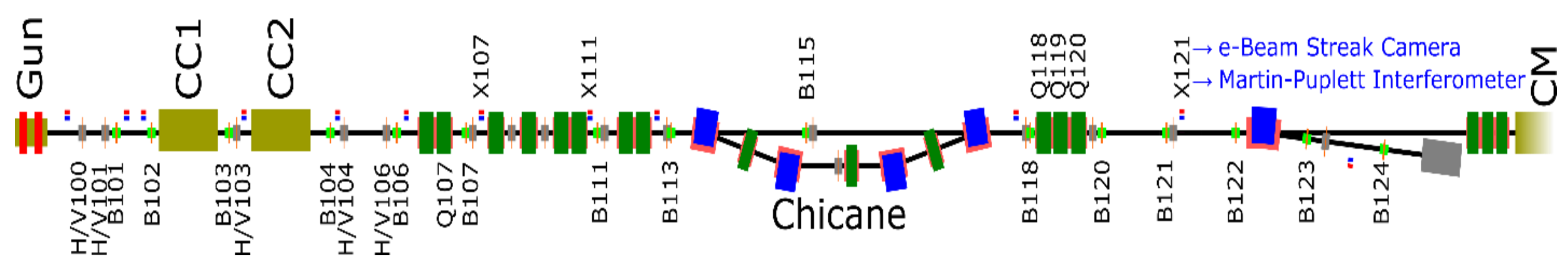




\section{Table 1. FAST Electron Beam Parameters for Studies}

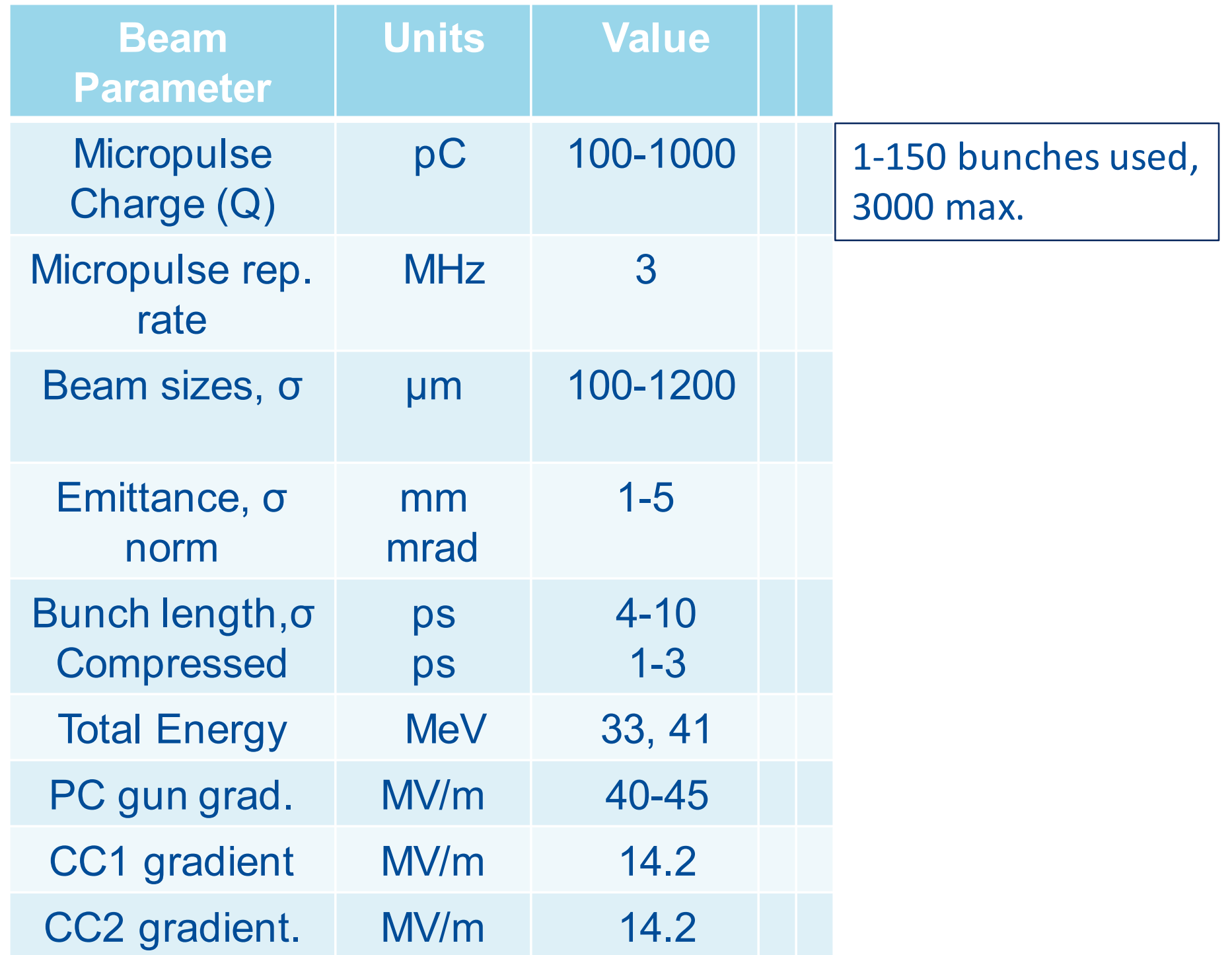


$>$ TESLA CAVITY

- 2 HOM couplers

\section{$>$ DIPOLE HOM}

- $V_{x}(t) \propto x \cdot e^{-\frac{t}{2 \tau}} \sin (\omega t)$

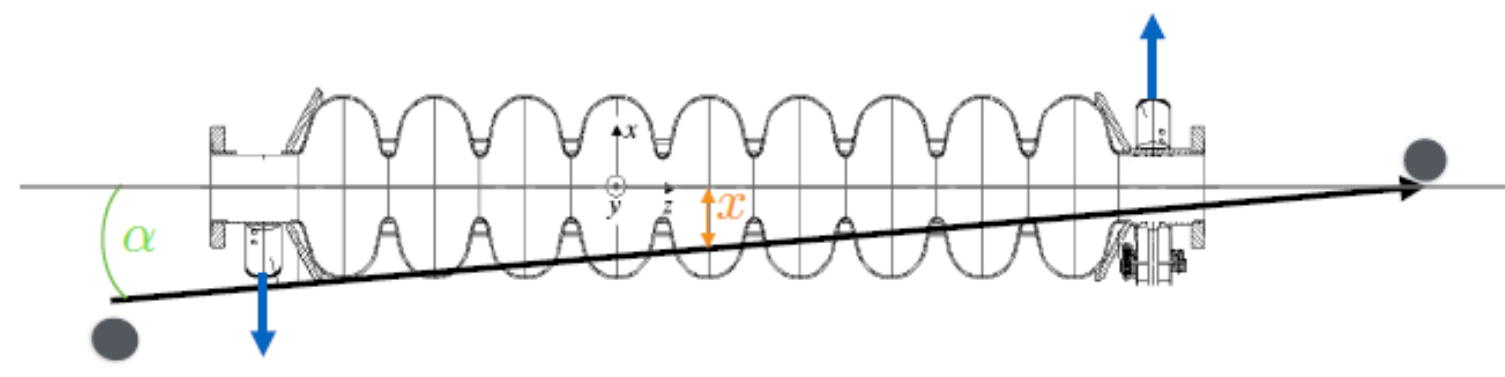

- $V_{x^{\prime}}(t) \propto x^{\prime} \cdot e^{-\frac{t}{2 \tau}} \cos (\omega t)$

Dipole Mode

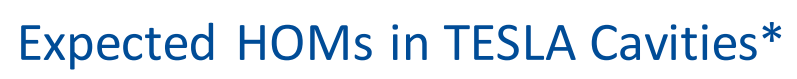
Mode \# Freq. $(\mathrm{GHz}) \quad \mathrm{R} / \mathrm{Q}\left(\Omega / \mathrm{cm}^{2}\right)$ MM-6 1.71 5.53

MM-7 1.73 7.78

$\mathrm{MM}-13$ 1.86

3.18

$\mathrm{MM}-14$

1.87

4.48

$\mathrm{MM}-30$

2.58

13.16

*R. Wanzenberg, DESY 2001-33
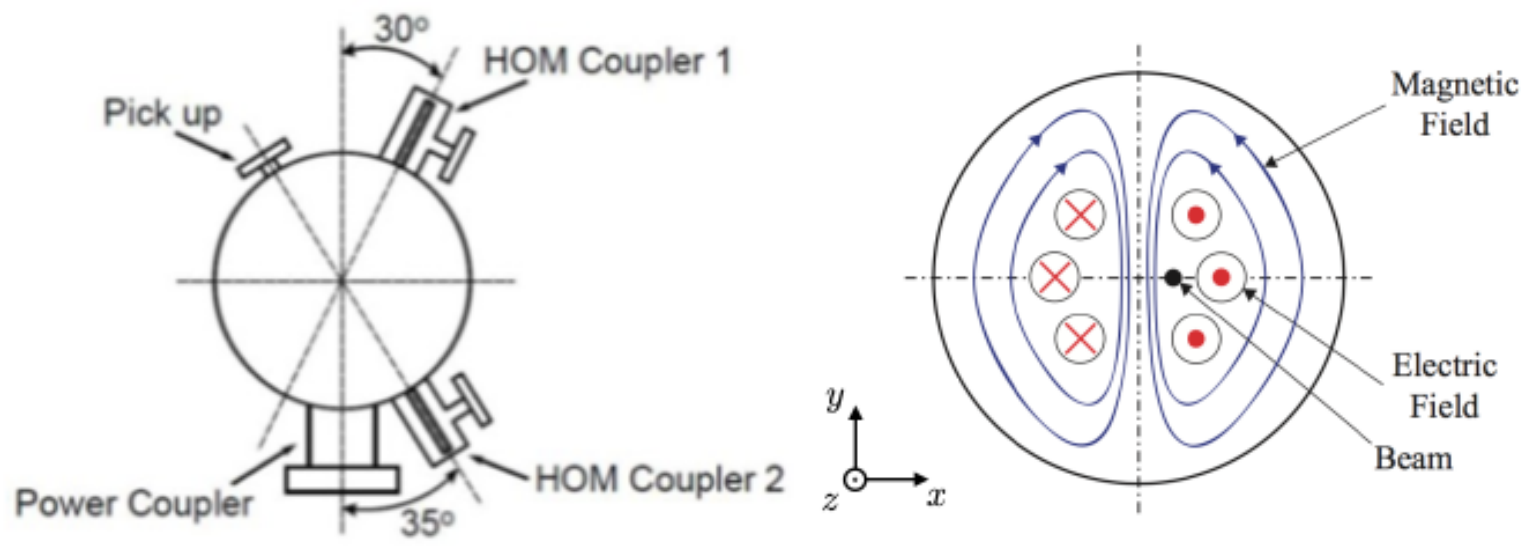

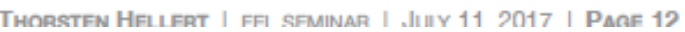

T. Hellert 7/11/17 DESY Seminar 


\section{Centroid Vertical Oscillations Observed to Grow with Drift}

- Comparison of sub-macropulse motion with corrector currents at $\mathrm{V} 101=-1,0,+1 \mathrm{~A}$. Correlation with excited HOMs. $1000 \mathrm{pC} / \mathrm{b}$

- Attributed to near resonance of beam harmonic and CC2 dipole mode 14 (A.H. Lumpkin et al., Phvs. Rev. A-B 21, June 2018).

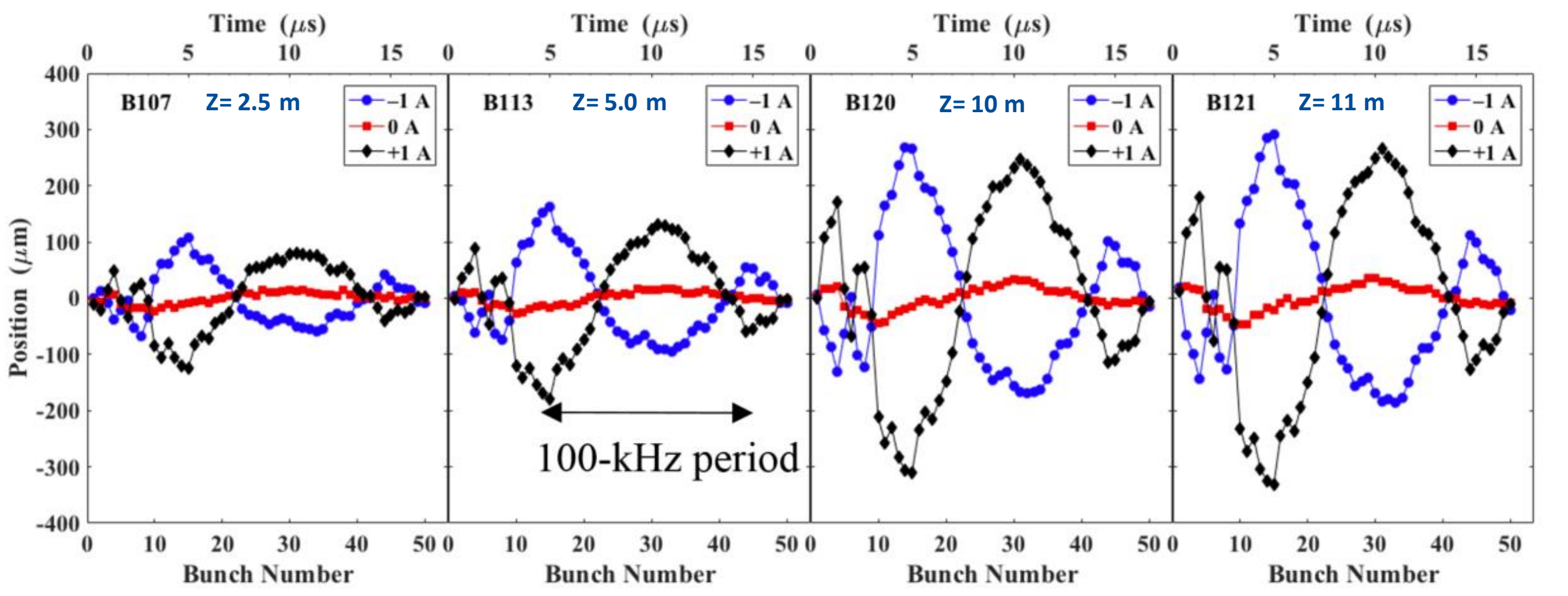

芓 Fermilab 


\section{Model of TESLA cavity for short-range transverse wakefields used to predict effect scale (Calculations by V. Lebedev)}

For $\mathrm{Q}=2.4 \mathrm{nC}$, sigma-t=10 ps, 1-mm offset, Beta- $\mathrm{x}=10 \mathrm{~m}$, get 40 - to $50-\mu \mathrm{m}$ kick within the micropulse from 1 TESLA cavity's wakefield.

\section{Lebedev Case:}

Cavity parameters

$\lambda_{\mathrm{p}}=25.02219 \mathrm{am}$

Nen $:=9$ cells per cavity

a: $=3.1 \mathrm{~cm}$

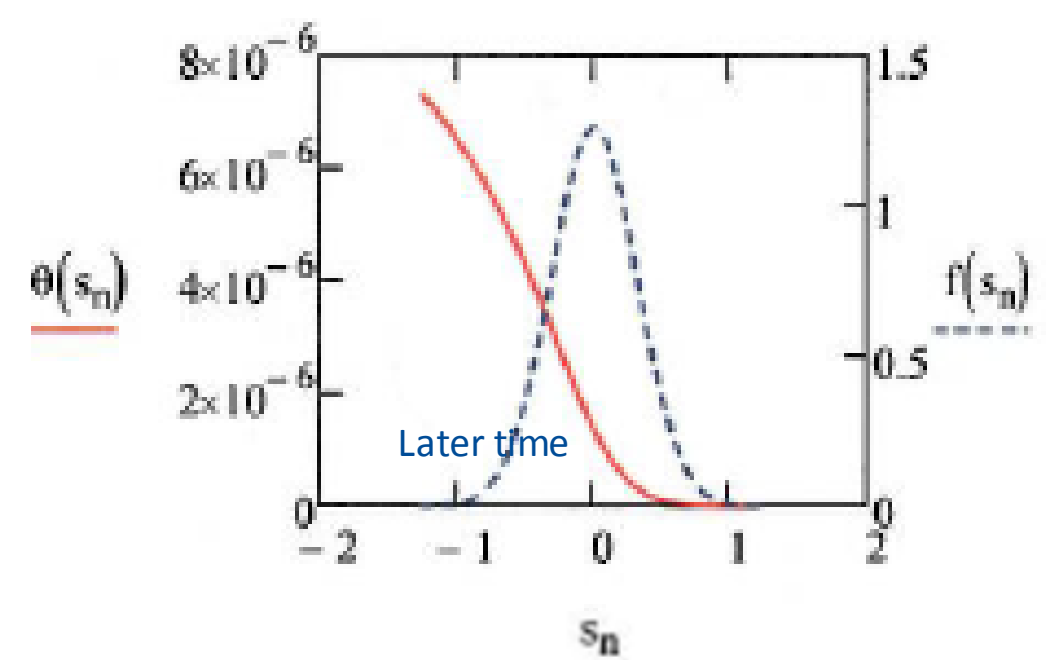

Transverse kick

$$
P_{0}=50 \cdot 10^{6} \quad \text { ev } \quad \Delta x=0.1 \mathrm{~cm}
$$

$$
\theta(\mathrm{s})=\frac{\mathrm{e}_{\text {cav }}-\mathrm{esgs}_{\mathrm{sg}} \mathrm{N}_{\mathrm{e}}}{\mathrm{P}_{0}} \int_{\mathrm{s}}^{10} \Delta \mathrm{x} \cdot \mathrm{w}_{\mathrm{T}}\left(\mathrm{s}_{\mathrm{p}}-\mathrm{s}\right) \cdot \mathrm{f}\left(\mathrm{s}_{\mathrm{p}}\right) \mathrm{ds} \mathrm{p}
$$

$\theta \mathrm{x}:=1000 \mathrm{~cm}$

$$
\mathrm{W}_{\mathrm{T}}(\mathrm{s}):=\frac{4 \cdot \mathrm{N}_{\text {cell }}}{\pi \cdot \mathrm{a}^{3}} \cdot\left[\frac{5}{4} \cdot\left[\sqrt{2 \cdot \mathrm{g} \cdot\left(\mathrm{s}+\frac{\mathrm{a}}{\gamma_{\text {eff }}}\right)}-\sqrt{2 \cdot \mathrm{g} \cdot \frac{\mathrm{a}}{\gamma_{\text {eff }}}}\right]-\mathrm{s}\right]
$$

Wake numerically computed for ILC cavities

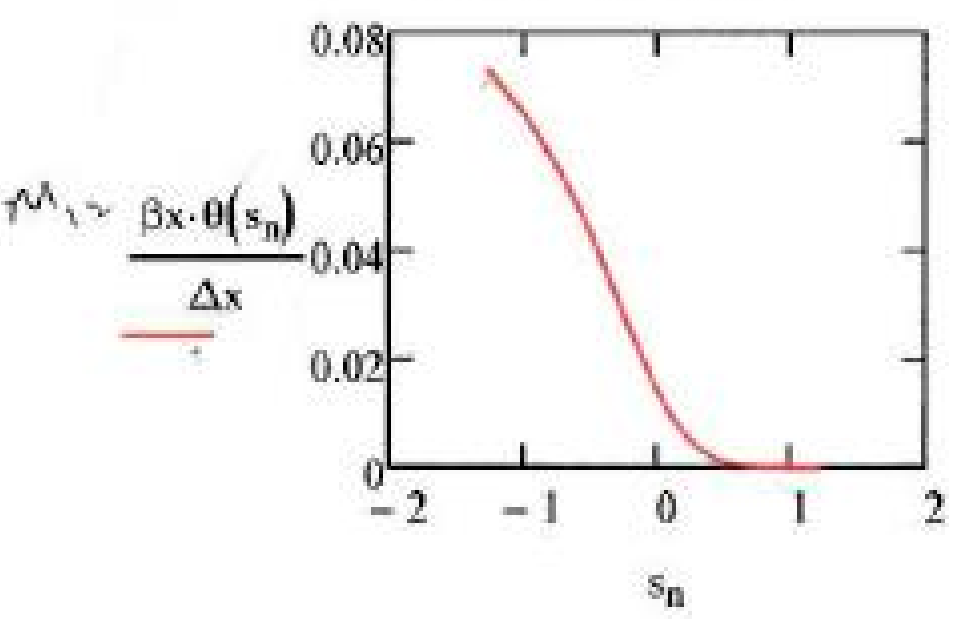

芓 Fermilab 


\section{Table of Scaled Short-Range Wakefield Kick Angles}

Table 1: Comparison of kicks vs $Q$ and offset referenced to Lebedev case 1 in one cavity at $50 \mathrm{MeV}$ so $1.5 \times$ for $33 \mathrm{MeV}$ in middle of CC2

\begin{tabular}{|c|c|c|c|c|c|c|}
\hline Case. No & $\begin{array}{l}\text { Charge } \\
\text { (pC) }\end{array}$ & $\begin{array}{l}\text { Offset } \\
(\mathrm{mm})\end{array}$ & $\begin{array}{l}\text { Beta-x } \\
(\mathrm{m})\end{array}$ & $\begin{array}{l}\text { Sigma-t } \\
\text { (ps) }\end{array}$ & $\begin{array}{l}\text { Kick } \theta \\
\text { (prad) }\end{array}$ & $\begin{array}{l}\text { Offset @ FWHM- } \\
\text { point } 2 \text { ( } \mu \mathrm{m}) \\
\mathrm{z}=10 \mathrm{~m}\end{array}$ \\
\hline 1 (ref.) & 2400 & 1 & 10 & 10 & 4 & 40 \\
\hline 2 & 2400 & 5 & 10 & 10 & 20 & 200 \\
\hline 3 & 1000 & 10 & 10 & 8 & 16 & 160 \\
\hline 4 & 3000 & 10 & 10 & 10 & 48 & 480 \\
\hline 5 & 500 & 5 & 20 & 10 & 4 & 80 \\
\hline
\end{tabular}

Such effects should be measurable with X121 OTR source and Synchroscan streak camera. 


\section{Initial tests for Short-range Wakefield Effects}

Initial tests for short-range wakefield effects generated by off-axis steering of the beam into $\mathrm{CC} 1$ and $\mathrm{CC} 2$. Localize to $\mathrm{CC} 2$ with V103 corrector.

- search for centroid shift within the 10-ps long micropulse.

- search for possible kick compensation by CC2.

- search for possible slice emittance effect.

- detect space-charge dominated regime and ellipsoidal beam.

- distinguish short-range wakefield centroid effect from HOMs' effect. 


\section{Initial conditions: HOMs as found, not minimized (03-01-19)}

- $\mathrm{V} 103=-0.30 \mathrm{~A}$, sig- $\mathrm{t}=56.2 \pm 0.7$ pixels $=>11.2$ ps with 0.20 ps/pix, 150b, 500 pC/b Sigma-y $=82 \pm 1$ pixels. y-t tilt. 10 ave.

$y$-t tilt:

$+343-\mu \mathrm{m}$

Shift, $\mathrm{H}-\mathrm{T}$.

$+9 \%$ beam size effect @ $495 \mu \mathrm{m}$

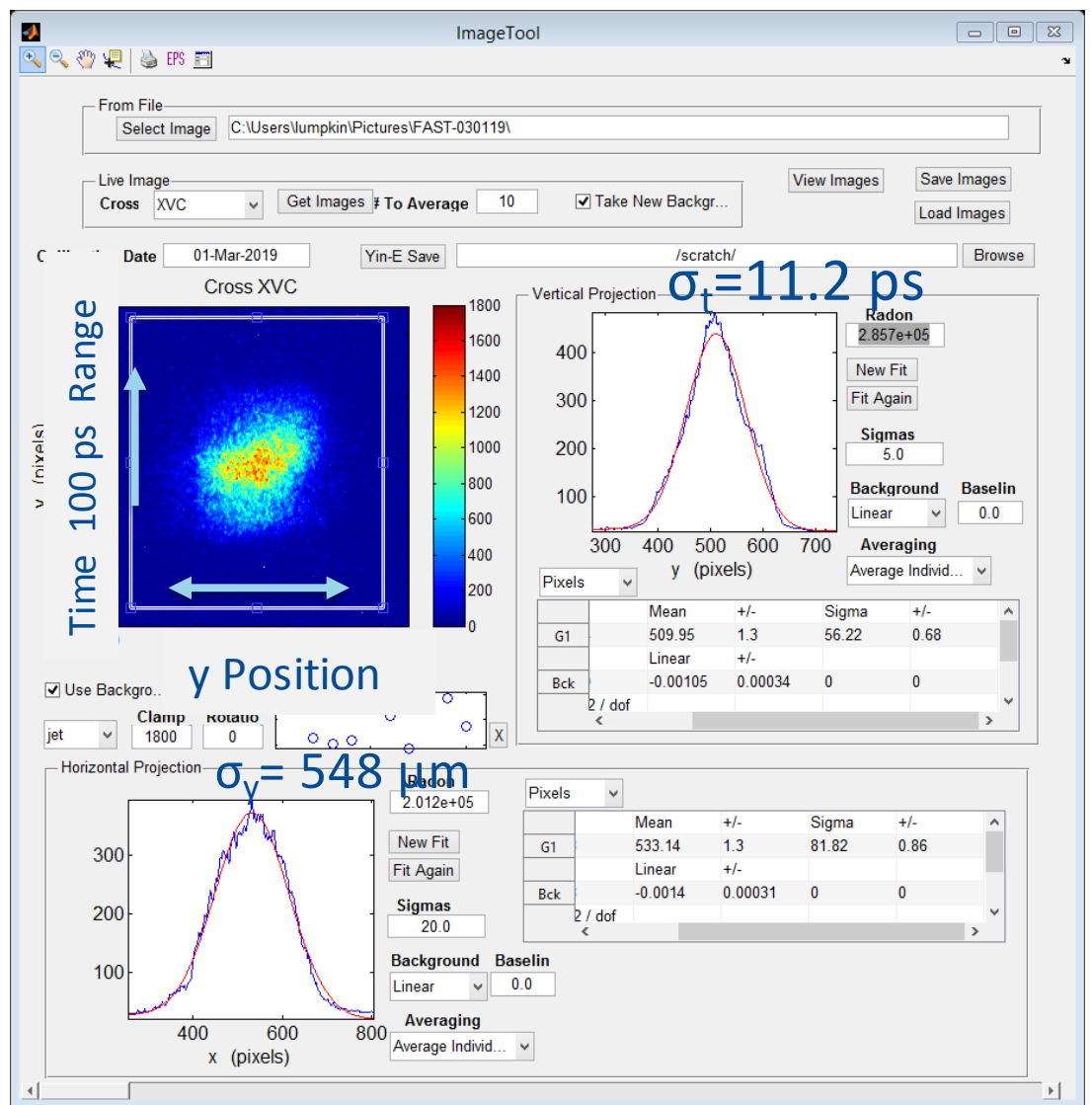

HOM Detectors $\mathrm{CC} 1[8]=-100 \mathrm{mV}$ $\mathrm{CC} 1[9]=-60 \mathrm{mV}$ $\mathrm{CC} 2[8]=-100 \mathrm{mV}$ $\mathrm{CC} 2[9]=-50 \mathrm{mV}$ 


\section{HOMs as Found: Effects of Steering Observed 3-01-19}

- It appears one can compensate the sub-micropulse scale kick in CC1 with one in CC2.

V103 $=-0.43 \mathrm{~A}$ as found

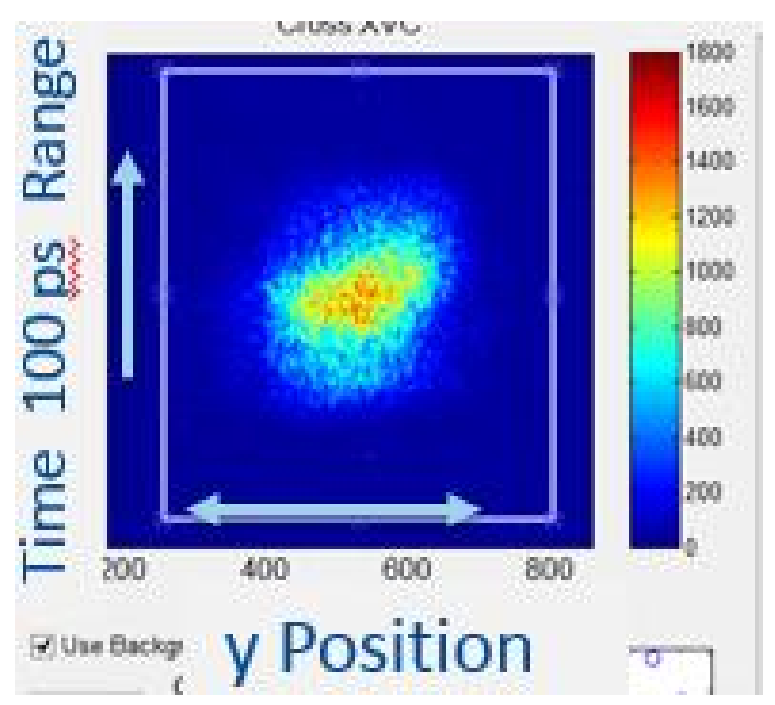

$\Delta \mathrm{V} 103=+2.4 \mathrm{~A}$

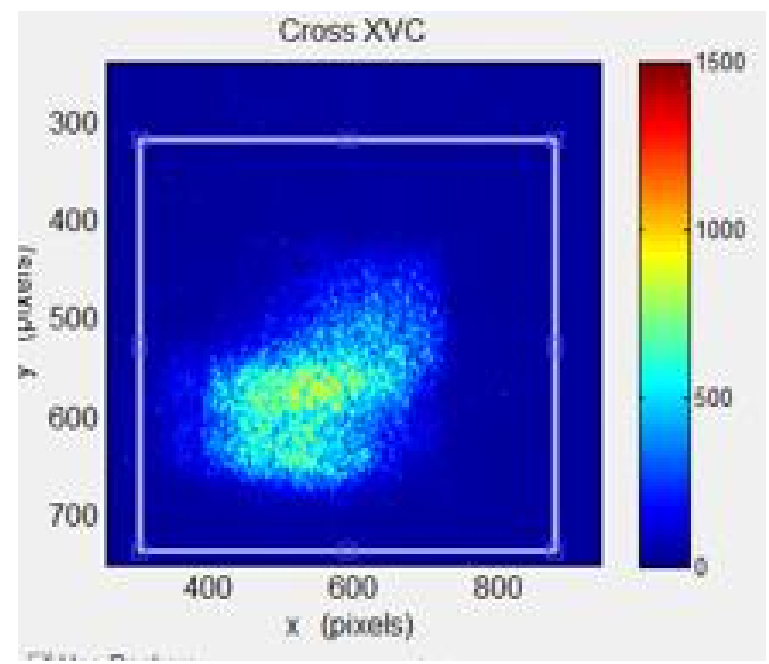

$\Delta \mathrm{V} 103=-2.4 \mathrm{~A}$

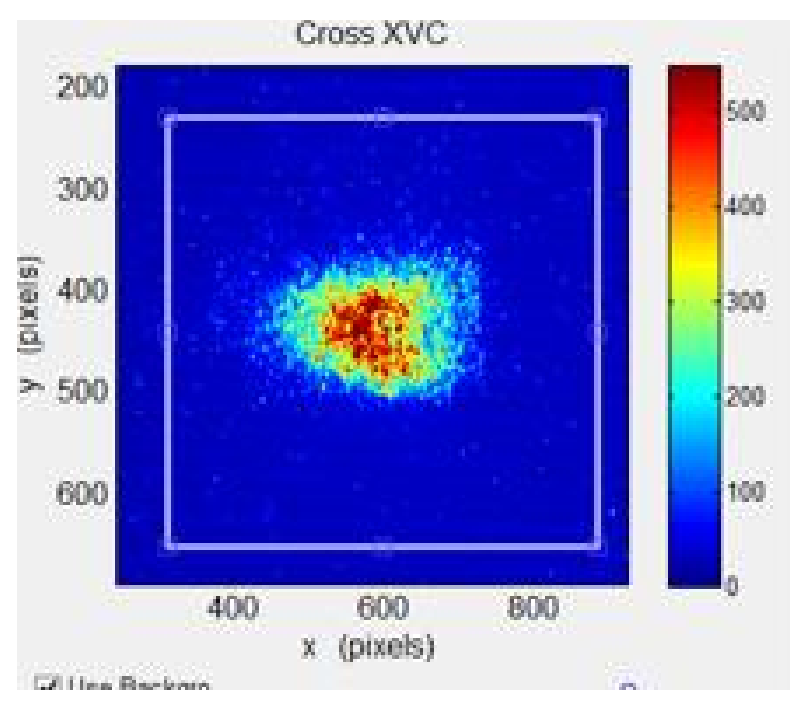




\section{HOMS as found, reference, $y-t$}

- Estimate mm+ off axis, angle with CC1 HOMs;100 mV, $60 \mathrm{mV}$ - Estimate mm+ off axis, angle with CC2 HOMs;100 mV, $50 \mathrm{mV}$
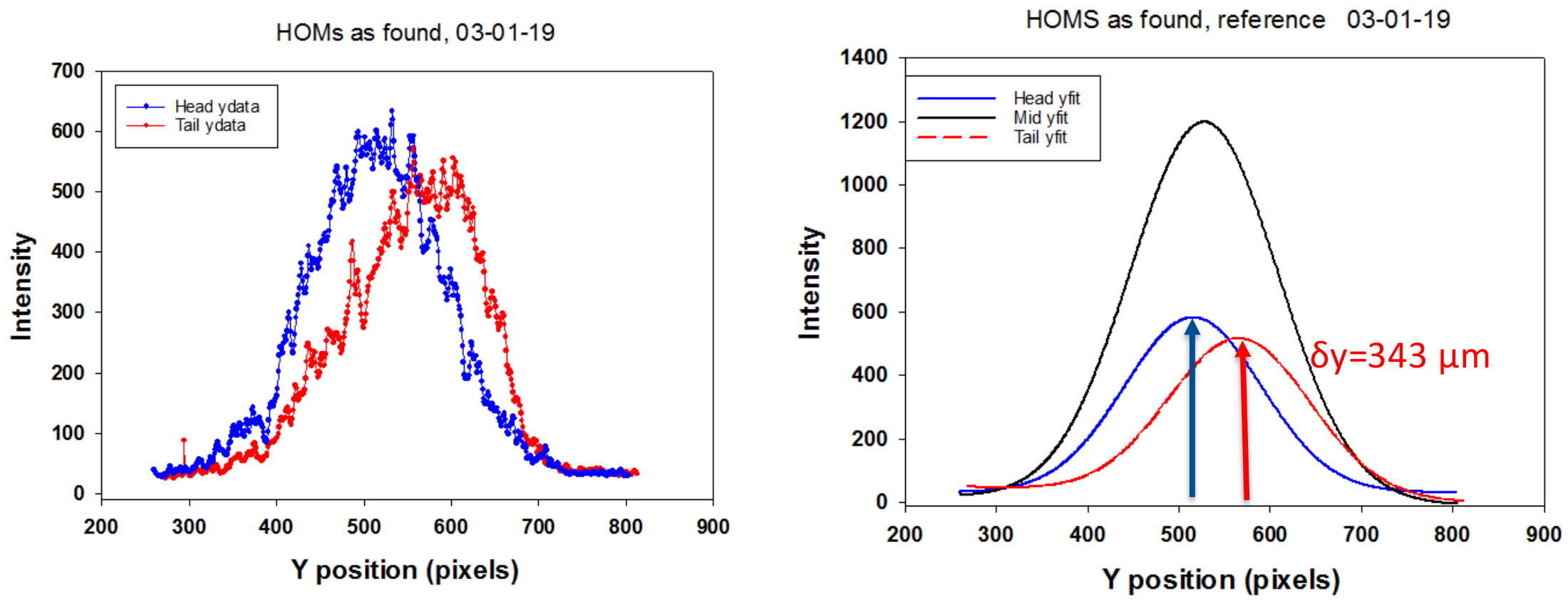


\section{Centroid Shifts within Micropulse Time: y-t $\quad$ 03-01-19}

- $\mathrm{V} 103=+2.4$ A from ref, $500 \mathrm{pC} / \mathrm{b}, 150 \mathrm{~b}, \mathrm{MCP}=61$

- Time samples of y profile at Head, Mid, and Tail of micropulse.
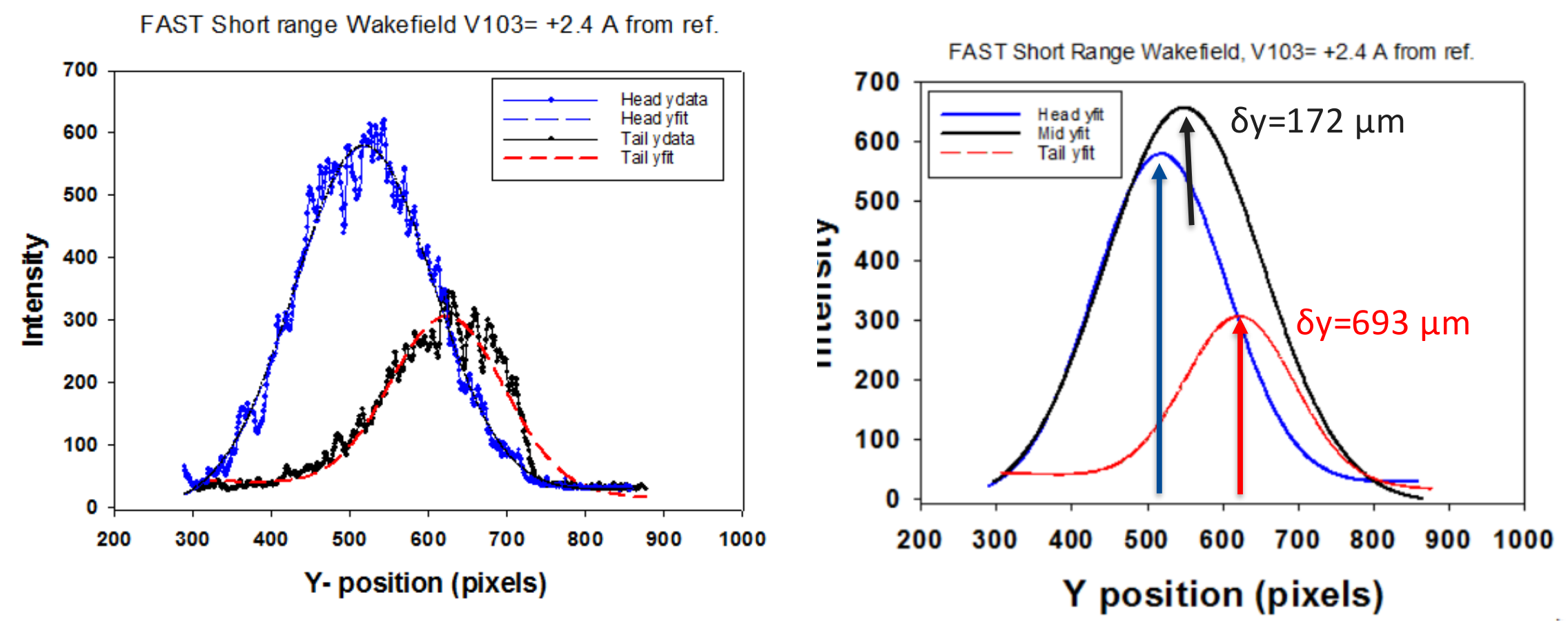


\section{Centroid Shifts within Micropulse Time: y-t $\quad$ 03-01-19}

- $\mathrm{V} 103=-2.4 \mathrm{~A}$ from ref, $500 \mathrm{pC} / \mathrm{b}, 150 \mathrm{~b}, \mathrm{MCP}=61$

- Time samples of y profile at Head, Mid, and Tail of micropulse.
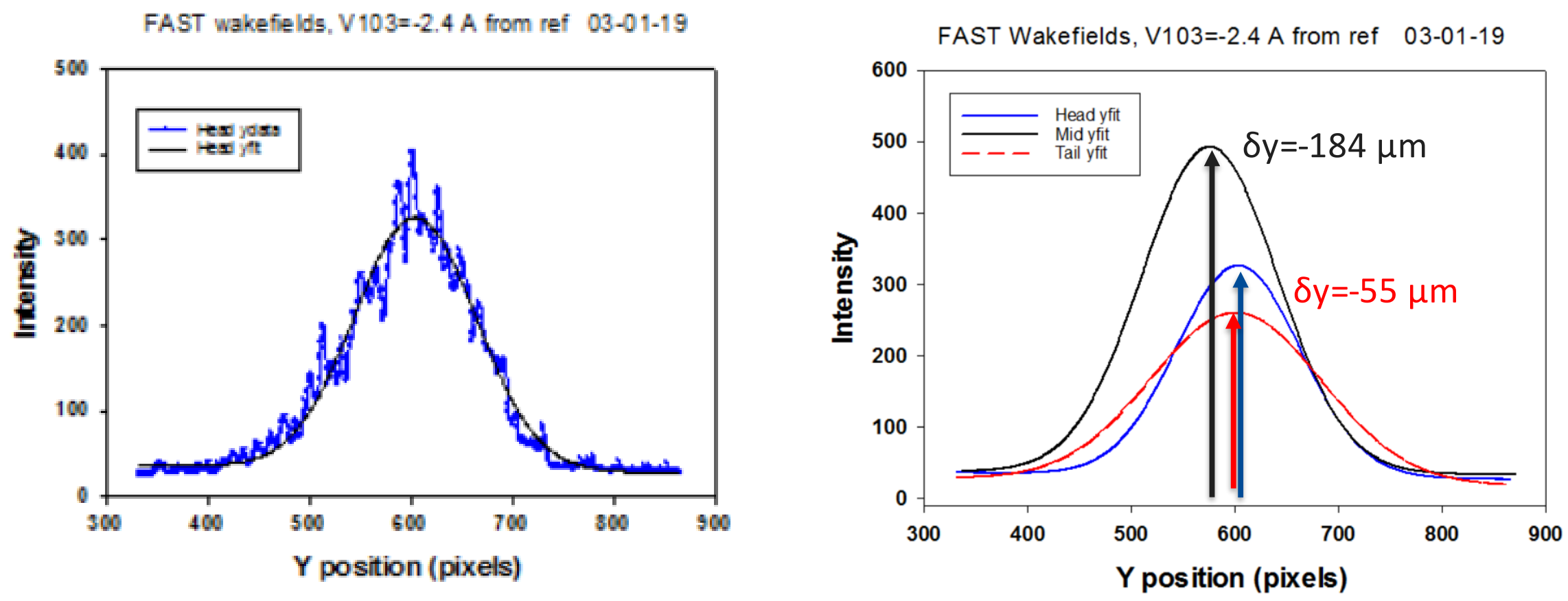
Combined Wakefield Effects of CC1 and CC2 Observed (03-01-19)

- Can one compensate kicks within micropulse time scale? Yes.

- Observations in X121 streak camera images $10 \mathrm{~m}$ downstream HOMs as found on 03-01-19: 500 pC/b, 150 b, $41 \mathrm{MeV}$ Total.

Table 1: Summary of V103, Beam Image parameters, HOMs

\begin{tabular}{|c|c|c|c|c|c|c|c|}
\hline Case \# & V103 (A) & $\begin{array}{l}\text { Head-tail y } \\
\text { centroid } \\
\text { shift ( } \mathrm{mm})\end{array}$ & $\begin{array}{l}\text { Projected y } \\
\text { size ( } \mathrm{mm})\end{array}$ & $\begin{array}{l}\text { CC1 } \\
\text { D1 } \\
(\mathrm{mV})\end{array}$ & $\begin{array}{l}\mathrm{CC} 1 \\
\mathrm{D} 2 \\
(\mathrm{mV})\end{array}$ & $\begin{array}{l}\text { CC2 } \\
\text { D1 } \\
(\mathrm{mV})\end{array}$ & $\begin{array}{l}\text { CC2 } \\
\text { D2 } \\
(\mathrm{mV})\end{array}$ \\
\hline 1 & $\operatorname{Ref}(-0.43)$ & 343 & 548 & -100 & -60 & -100 & -45 \\
\hline 2 & +2.4 delta & 681 & 643 & -100 & -55 & -204 & -40 \\
\hline 3 & - 2.4 delta & -55 & 466 & -100 & -58 & -214 & -105 \\
\hline
\end{tabular}

Cases 1-3: 16\% size reduction, Cases 2-3: 38 \% reduction.

After CC2, rf BPM B104 $=+7.4 \mathrm{~mm}$ for case $2,-12.4 \mathrm{~mm}$ for case 3 


\section{Initial conditions: HOMs minimized}

- $\mathrm{V} 103=0.054 \mathrm{~A}$, sig- $\mathrm{t}=60.3 \pm 0.5$ pixels $=>11.8$ ps with 0.20 ps/pix, 50b, 500 pC/b, Sigma-y $=57 \pm 1$ pixels. No y-t tilt. $10 i$.

No y-t tilt: Ellipsoidal beam

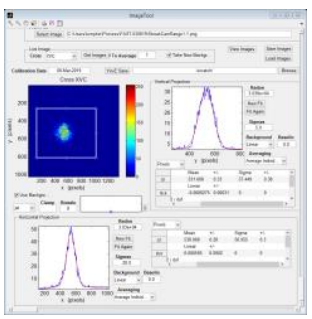

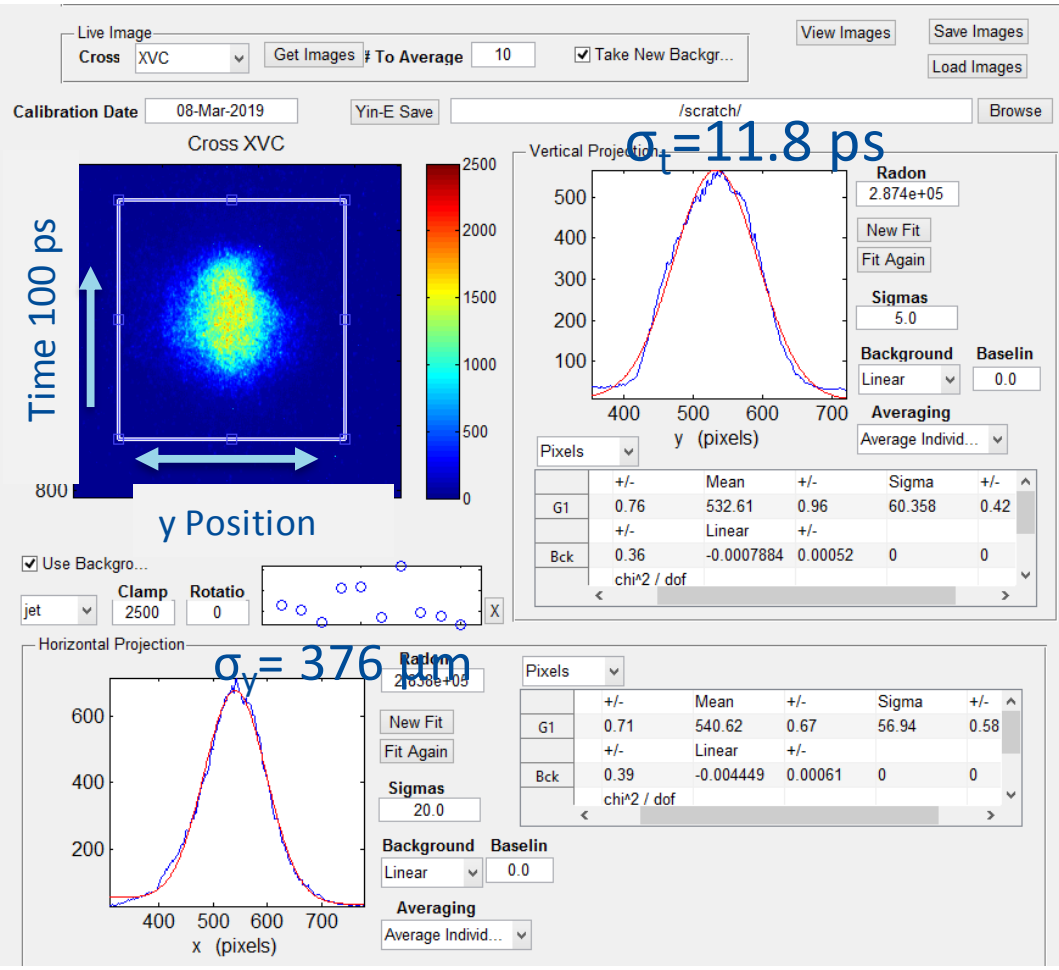

HOM Detectors $\mathrm{CC} 1[8]=-13 \mathrm{mV}$ $\mathrm{CC} 1[9]=-10 \mathrm{mV}$ $\mathrm{CC} 2[8]=-5 \mathrm{mV}$ $\mathrm{CC} 2[9]=-7 \mathrm{mV}$ 


\section{$y(t)$ Centroid Shift and Slice Profile Growth Seen $\quad 3-17-19$}

- Comparison of $\mathrm{V} 103=-0.05$, delta-2A images show a $-106 \mu \mathrm{m}$ centroid shift and width change of $+140 \mu \mathrm{m}$ at tail.

- Observed changes would be $260 \%$ slice emittance effect.
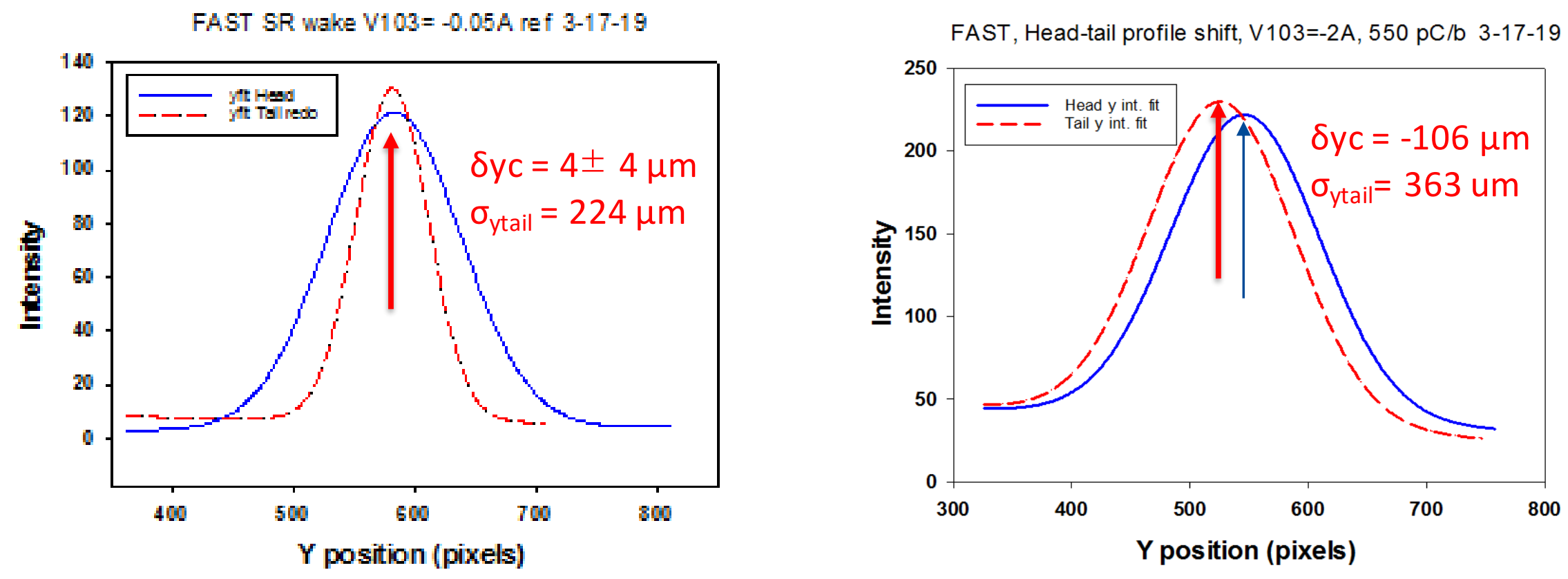


\section{0-shot Average rf BPM for HOM-induced motion at B121}

- 550 pC/b, 50 b, V103= -2A, +2A. 4-mrad kick angle into CC2.

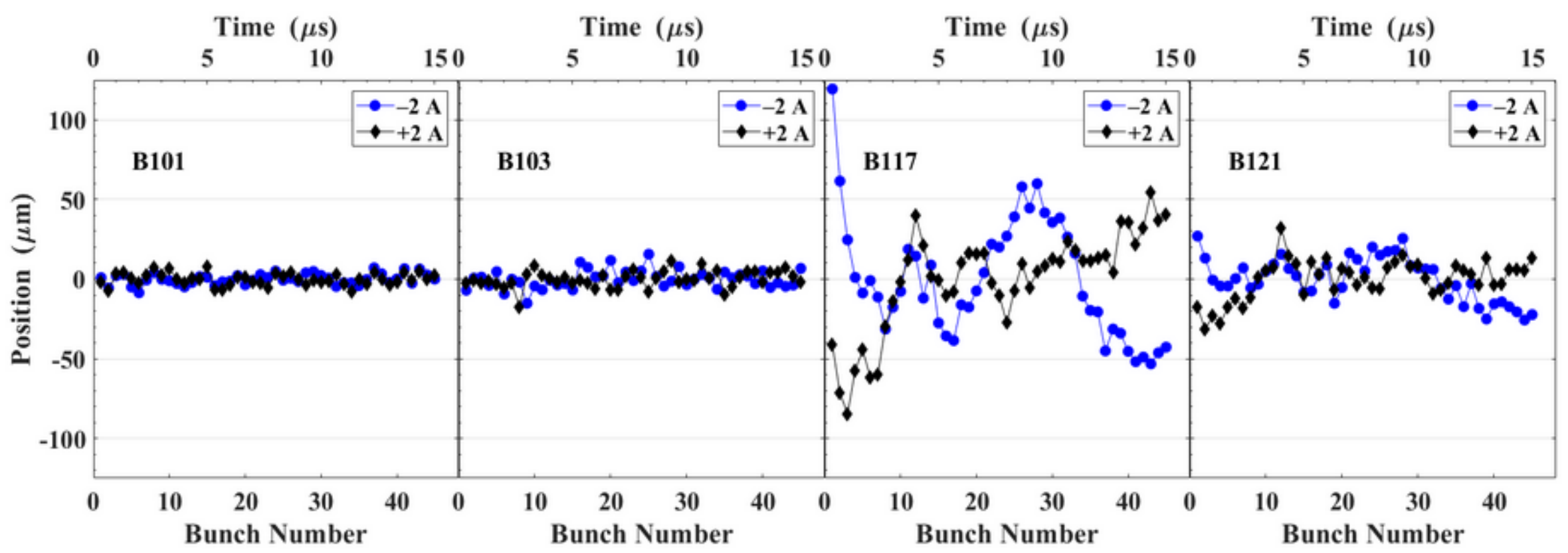

$<20 \mu$ m centroid motion at B121, average effect even smaller.

*Data has 50-b mean subtracted. 


\section{Schematic of the Planned Full LCLS-II Injector}

- Potential short-range and long-range wakefields due to off-axis beam in cavities need to be minimized to preserve emittance.

- HOMs in CM01 tracked. Steering at 1-8 MeV critical in first 3 cavities. Cavity 1 at $8 \mathrm{MV} / \mathrm{m}$; Cavities 2,3 at $0 \mathrm{MV} / \mathrm{m}$; Cavities 4-8 at $16 \mathrm{MV} / \mathrm{m}$. Commissioning expected in Fall 2020.
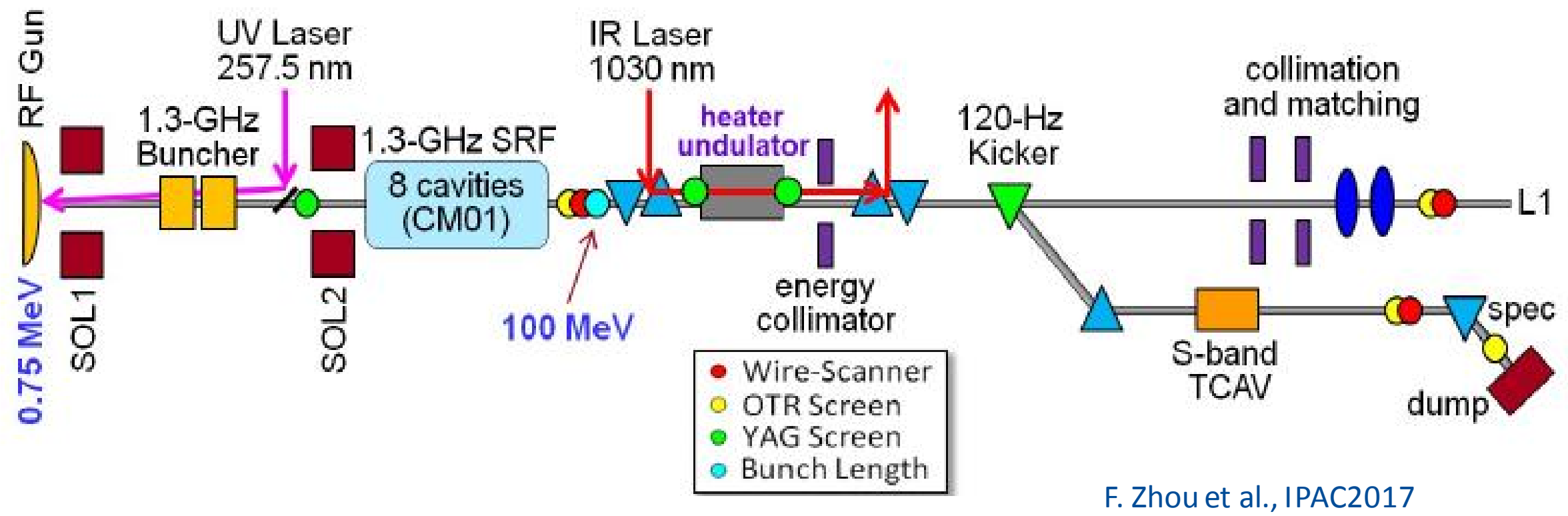

荤 Fermilab 


\section{SUMMARY}

- Generated and measured y-t effects consistent with short range wakefields calculated with a numerical model.

- Evidence for sub-micropulse centroid shifts and slice emittance effects. Unique results for TESLA-type cavity.

- Demonstrated kick compensation in CC2 within micropulses.

- Further studies with laser spot size and the position on cathode under control needed and with single bunches.

- Coordinated data with laser control, rf BPMs, HOMs, streak camera, etc. needed. Establish/monitor minimum HOM setup.

- Relevance to LCLS-II injector commissioning noted with their $<1 \mathrm{MeV}$ beam injection into a buncher and a cryomodule. Preliminary discussions on possible collaboration held in May. 


\section{ACKNOWLEDGEMENTS}

The authors acknowledge the wakefield calculations of V. Lebedev; technical support of J. Santucci, D. Crawford, and B. Fellenz; the project support of J. Liebfritz; the mechanical support of $\mathrm{C}$. Baffes; the lattice assistance of S. Romanov; the cold cavity HOM measurements of $\mathrm{A}$. Lunin and T. Khabiboulline of the Technical Division, the SCRF support of E. Harms; discussions with S. Yakovlev; as well as the discussions with and/or support of A.Valishev, D. Broemmelsiek, V. Shiltsev, and S. Nagaitsev of the Accelerator Division at Fermilab. The Fermilab authors acknowledge the support of Fermi Research Alliance, LLC under Contract No. DE-AC02$07 \mathrm{CH} 11359$ with the United States Department of Energy. 


\section{Backup and Extra Slides}

- Ellipsoidal beam

- Source images for different conditions.

- LANL short-range wakefield data, NC L-band.

- HOM data logger

- HOM model results

- etc. 


\section{Head-tail Effect at V103= +3 A $\quad 500 \mathrm{pC} / \mathrm{b} \quad 03-08-19$}

- V103=+3A head to tail centroids: $576.4,581.0,564.4$ pix sigmas $25,50.1,26.2$ pix
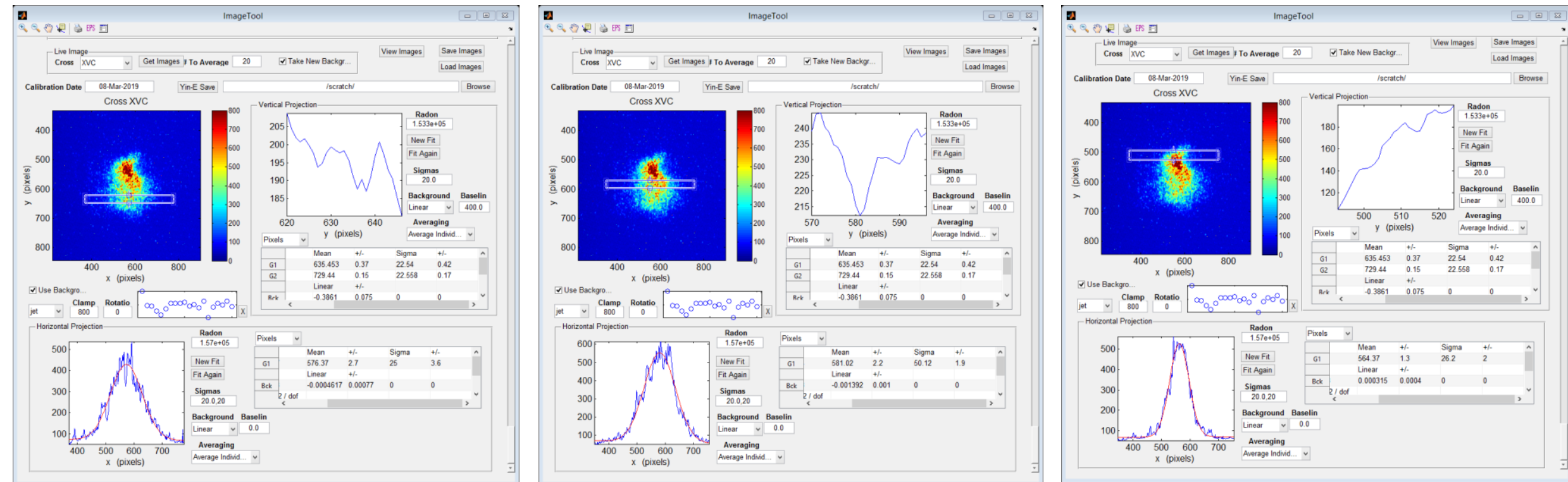

Ellipsoidal shape perturbed by short range wakefields. HOMs only $20 \mu \mathrm{m}$ oscillation generally at $\mathrm{Q}$ and V103 setting 


\section{Head tail kick at V103=+3A from reference 20 Image ave}

- Centroid shift observed from head to tail: $-79 \mu \mathrm{m}$.

- Centroid shift observed from midpoint to tail: $-112 \mu \mathrm{m}$
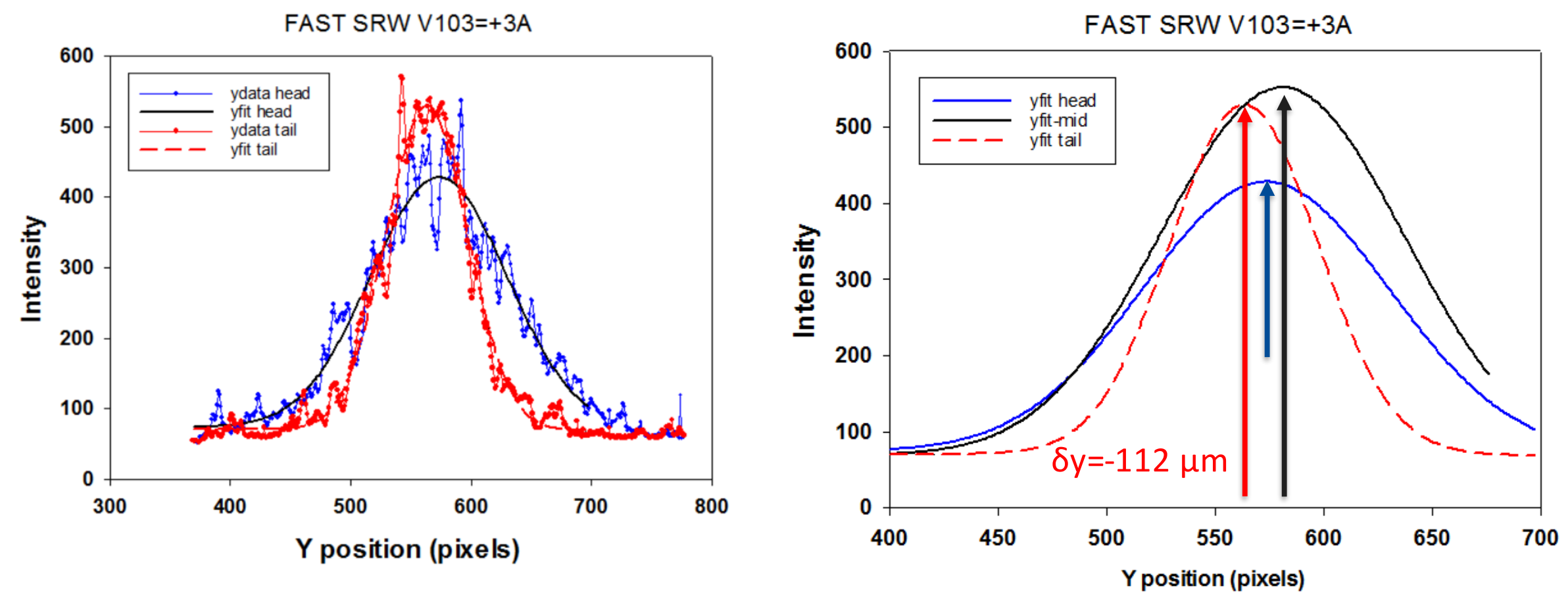


\section{Search for Short Range y-t effect in Streak Camera Images}

- V103=0.05 A, 550 pC/b, 150 b, 5 images, Reference. 3-17-19

- Head-tail delta Gaussian peaks +0.6 \pm 0.5 pix $=>+4 \pm 4 \mu \mathrm{m}$

- beam size changes in $\mathrm{t}$, Head $=370 \mu \mathrm{m}$, tail $=224^{*} \mu \mathrm{m}$
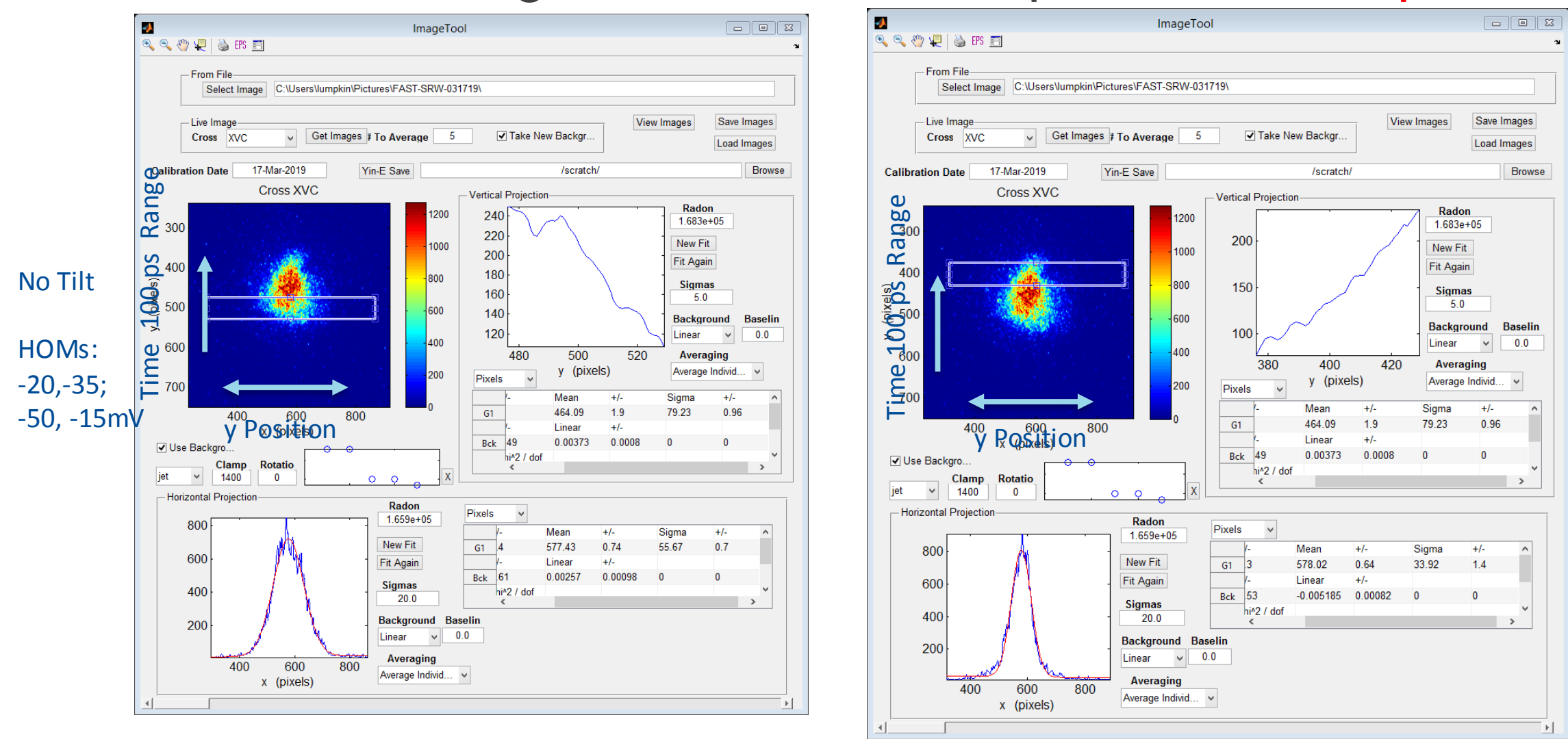


\section{Search for Short Range y-t effect in Streak Camera Images}

- $\mathrm{V} 103=-2 \mathrm{~A}, 500 \mathrm{pC} / \mathrm{b}, 50 \mathrm{~b}, 10$ images 3-17-19

- Head-tail delta Gaussian peaks $\sim-16$ pixels => -106 $\mu \mathrm{m}$

- Min. beam size changes in t, Head $=389 \mu \mathrm{m}$, tail $=363 \mu \mathrm{m}$,
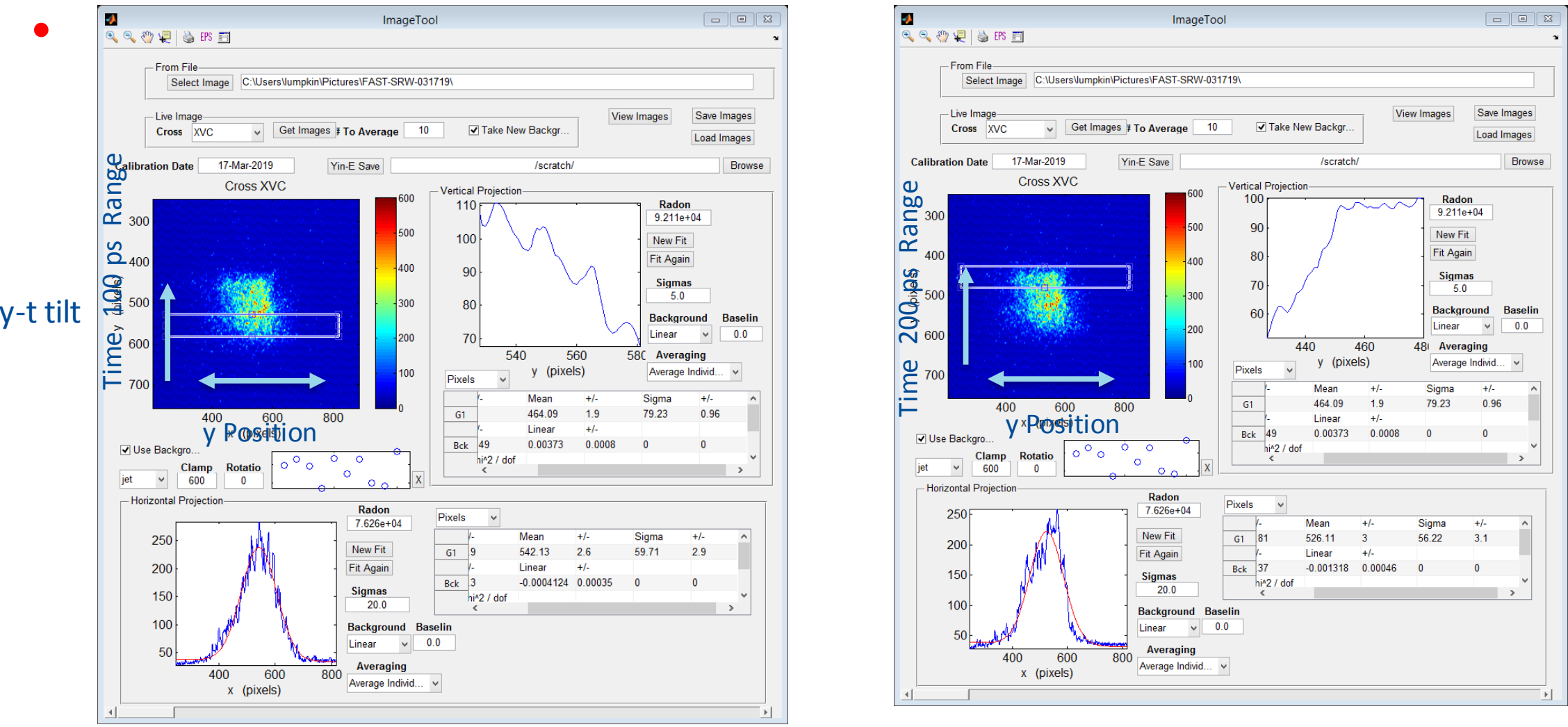


\section{LANL Short range Wakefield Experiment}

- Streak camera diagnostic shows head-tail kick and observed emittance growth and reduction with steering through cavity 4 .

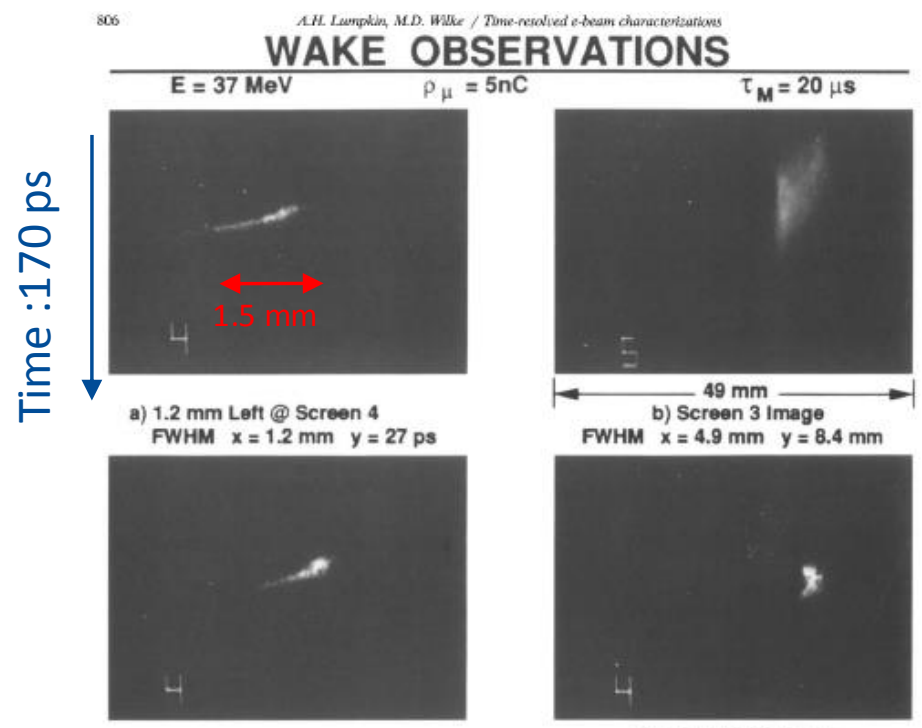

c) Centered Through Linac

FWHM $x=0.76 \mathrm{~mm} \quad y=26 \mathrm{ps}$

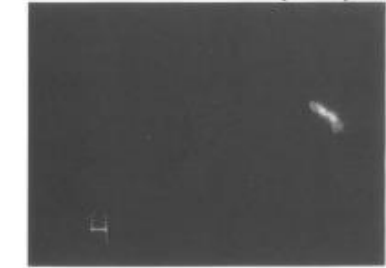

e) $1.2 \mathrm{~mm}$ Right @ Screen 4

FWHM $x=0.81 \mathrm{~mm} \quad y=27 \mathrm{ps}$

"Corrected" Position

d) $1.3 \mathrm{~mm}$ Right @ Screen 4

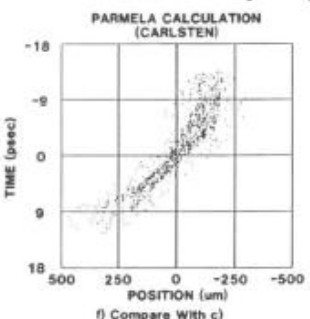




\section{HOM Detector Signals tracked during run}

- CC1 detector signals stable after 21:00 when laser stabilized.

- CC2 detectors show effects of V103 current changes.
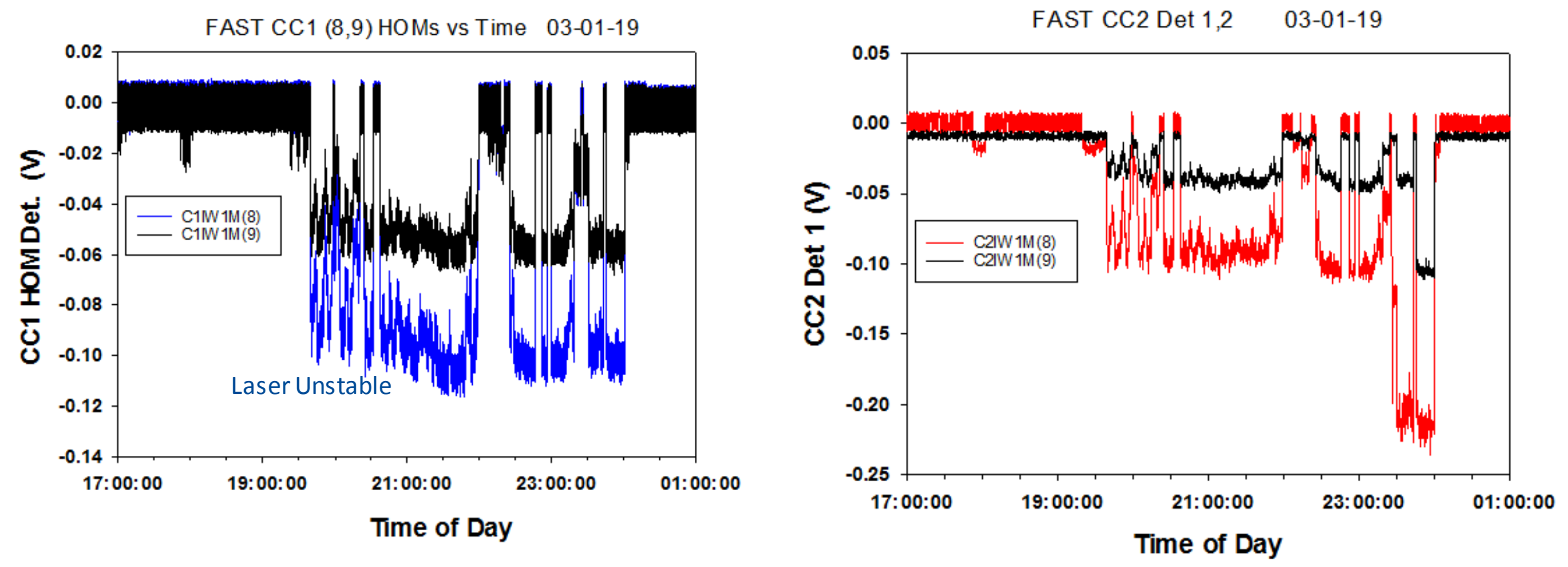


\section{CC2 and CC1 Generated Dipole HOM Kicks (Calculations)}

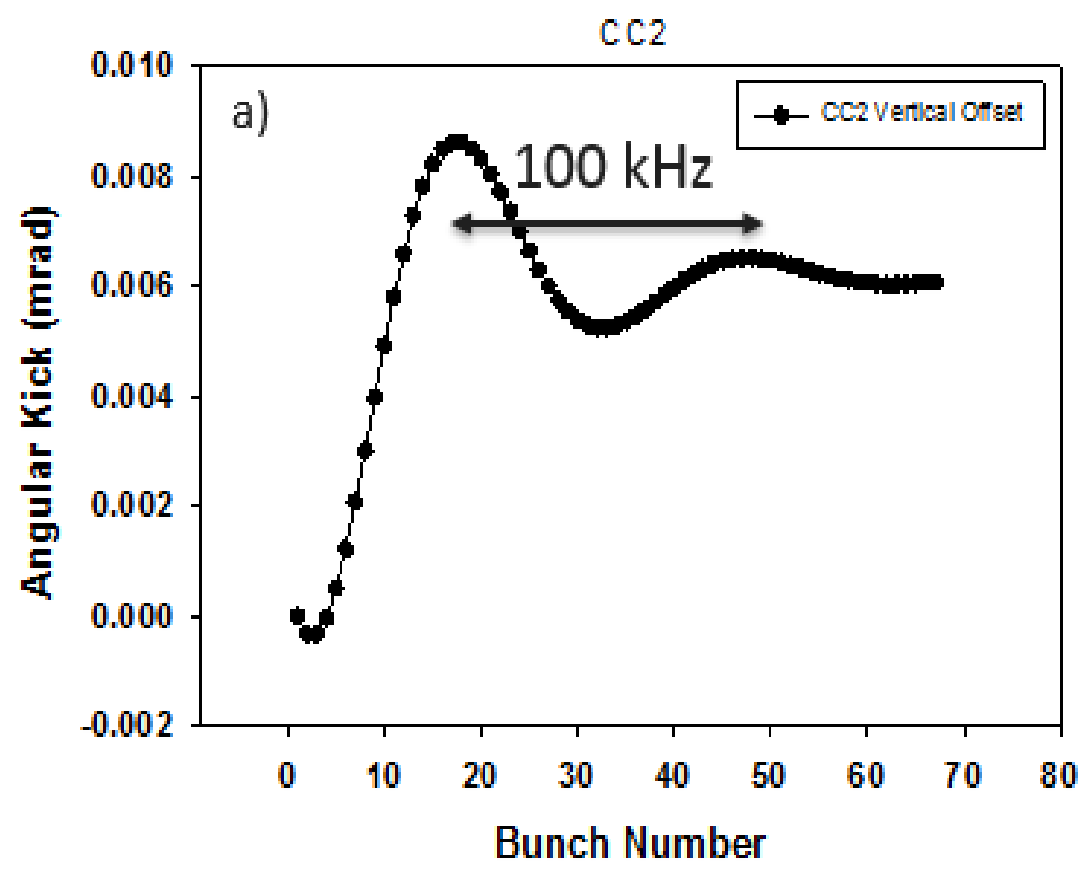

CC2: MM-14 with vertical polarization, $5 \mathrm{~mm}$ translation, $500 \mathrm{pC} / \mathrm{b}$. Beam sampling at $3.008 \mathrm{MHz}$, harmonic \# 623 within $100 \mathrm{kHz}$ of the HOM frequency.

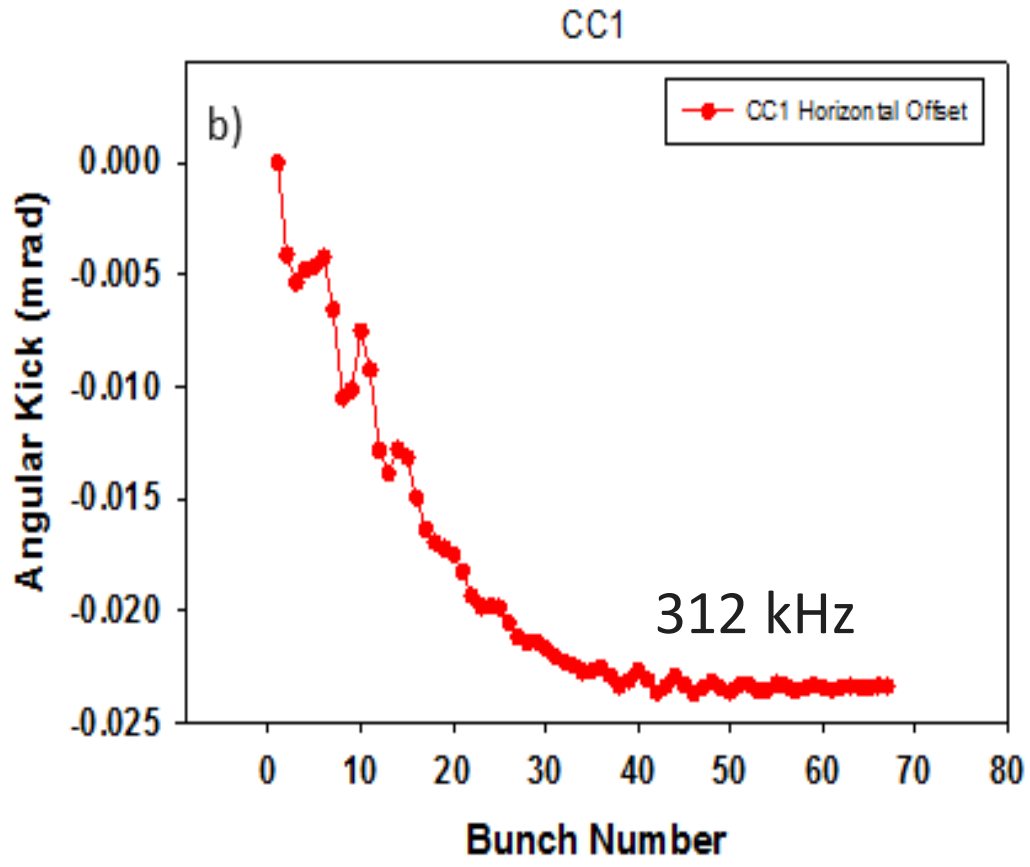

CC1: MM-7 plus MM-30; $5 \mathrm{~mm}$ translation, $500 \mathrm{pC} / \mathrm{b}$. 